\title{
Association between dietary glycemic load and metabolic syndrome in obese children and adolescents
}

\author{
Angela Cornejo-Monthedoro ${ }^{a}$ B.C., Isel Negreiros-Sánchez ${ }^{a}$ B.C., \\ Carlos Del Águilab, M.D., Marlit Ysla-Marquillo ${ }^{b}$ M.D. and Percy Mayta-Tristána, ${ }^{c}$ M.D.
}

\begin{abstract}
Objective. To study the association between the metabolic syndrome (MS) and the glycemic load (GL) of food intake among obese children and adolescents seen in consultation by the endocrinology team in a pediatric referral hospital in Lima, Peru.

Population and Method. Cross-sectional study among obese children and adolescents (body mass index $\geq 95$ percentile), 10-15 years old. The MS was classified according to criteria of the International Diabetes Federation. A 24 hour reminder was used, and the overall and per meal GL was calculated. The association between the GL tertiles (comparison with the lower tertile) and the MS was assessed using prevalence ratios adjusted by demographic outcome measures, family history, physical activity and total carbohydrate consumption in Poisson regression models with a robust variance.

Results. Out of 273 obese children and adolescents, $52.4 \%$ were male and $94.9 \%$ did not engage in any physical activity. Glycemic load median value was 213 (164.8-287.4) and the daily calorie intake value was 2275 (1851-3024) $\mathrm{kcal}$, consisting mainly of carbohydrates $(62 \%)$. MS prevalence was $22.3 \%$; the most prevalent components were abdominal obesity $(81.7 \%)$ and low values of high density lipoprotein (HDL) $(63.7 \%)$. Lastly, an association was observed between a high consumption of GL and the risk of developing MS (aRP 4.5; 95\% CI: 1.3-15.3).

Conclusions. There is an association between a high consumption of GL and the presence of MS among obese children and adolescents.

Key words: metabolic syndrome, adolescents, obesity, food intake, glycemic load.
\end{abstract}

http:/ / dx.doi.org/10.5546/ aap.2017.eng.323

Peruana de Ciencias Aplicadas, Lima,

Peru.

E-mail address:

Angela Cornejo-

Monthedoro,

angela_022007@

hotmail.com

Funding:

None.

Conflict of interest:

None.

Received: 7-10-2016

Accepted: 1-16-2017

To cite: Cornejo-Monthedoro A, Negreiros- Sánchez I, Del Águila C, et al. Association between dietary glycemic load and metabolic syndrome in obese children and adolescents. Arch Argent Pediatr 2017;115(4):323-330.

\section{INTRODUCTION}

Obesity in children and adolescents has become a pandemic. It causes adverse consequences on health, both in these stages and in adulthood, and it is a risk factor for the development of chronic diseases. ${ }^{1}$ It has several causes, such as an imbalance between caloric intake and expenditure. ${ }^{1}$

It has been shown that the diet of obese children and adolescents is based on highly caloric foods high in carbohydrates and fat. For example, in Mexico and Argentina, the diet includes rice, cookies, legumes and cereals more frequently and in larger quantities; these foods represent a high percentage of the diet of an obese patient. ${ }^{2,3}$

Metabolic syndrome (MS) is a disorder that consists of a cluster of metabolic abnormalities that occur together, increasing the risk of coronary heart disease and diabetes. MS is more prevalent in obese children and adolescents (29.2\%), than in non-obese patients (11.9\%). ${ }^{4}$ Each MS component is an independent risk factor for cardiovascular disease. The coexistence of several of these components has a synergistic effect on the atherogenic risk. ${ }^{5,6}$ MS in children and adolescents has been defined by several institutions and authors. ${ }^{7}$

MS is directly related to insulin resistance which, in turn, is related to postprandial hyperglycemia. Spikes of postprandial glucose levels are linked to meal glycemic load (GL); therefore, the prolonged intake of high GL foods may be associated to the development of insulin resistance and MS. ${ }^{8}$

Glycemic load is used to quantify the impact of a serving of food with a determined glycemic index (GI) value. GI measures the capacity of a 
carbohydrate to raise blood glucose levels after its intake, by comparing it to a standard reference food, such as pure glucose or white bread. ${ }^{9}$ Thus, GL value shows the quality and quantity of carbohydrates available in the food. ${ }^{10}$

Even though there is a study that found an association between GL and MS in female adolescents, ${ }^{8}$ no studies have been conducted in obese children and adolescents. Since this is a population with a higher intake of high GL foods and a higher frequency of MS, this association should be more evident. ${ }^{4}$ Therefore, our goal was to evaluate the association between MS and GL in the food eaten by this population.

\section{POPULATION AND METHODS}

\section{Study design and location}

An analytic cross-sectional study was performed between November 2014 and August 2015 , in obese children and adolescents seen in consultation by the endocrinology team at the National Institute of Child Health (Instituto Nacional de Salud del Niño, INSN). This is a national pediatric referral center of the Ministry of Health of Peru, located in Lima.

\section{Population and sample}

The study included all patients between 10 and 15 years old, treated at the endocrinology outpatient offices of INSN for the first time, with a body mass index $(\mathrm{BMI}) \geq 95$ percentile. Data were evaluated with the WHO AnthroPlus software. ${ }^{11}$ Patients previously diagnosed with diabetes mellitus 1 and 2 were excluded, since they were already under medical and nutritional treatment. Patients with endocrine, neurological and genetic disorders were also excluded, as well as those who opted out of the study. In addition, only patients with results for all the biochemical tests necessary for the diagnosis of MS components were included.

The minimum sample size was estimated as 270 subjects, using the PASS v13.0 software, with the formula to calculate the prevalence ratio (PR) using the Poisson regression model. A PR of 2.0 was considered the worst scenario, with a $95 \%$ confidence level, a power of $80 \%$, an $\mathrm{r}^{2}=0.10$ in the adjustment of outcome measures, and an MS prevalence of $22.9 \% .{ }^{12}$ Considering the possibility that a group of patients would refuse to take part in the study, or the unavailability of biochemical tests in their medical records, an additional 15\% of patients were invited to participate, that is, 311 obese patients. Patients were consecutively enrolled in census-like fashion. Since the study included untreated obese patients, the treating physician, following the study protocol, indicated biochemical tests including blood glucose and complete lipid panel.

\section{Metabolic syndrome and its components}

Five MS components were evaluated: (a) baseline glucose, (b) triglycerides and (c) HDL cholesterol, which were recorded in the clinical records, (d) waist circumference, measured as per Lohman et al., ${ }^{13}$ and analyzed according to the table by Fernández et al., ${ }^{14}$ and (e) arterial blood pressure, recorded by investigators following the Pan American Health Organization recommendations. ${ }^{15}$ According to the criteria of the International Diabetes Federation (IDF), ${ }^{7}$ MS was present when patients had a waist circumference $>90$ percentile (abdominal obesity) and two or more additional criteria, such as triglycerides $\geq 150 \mathrm{mg} / \mathrm{dl}$, HDL cholesterol $<40 \mathrm{mg} / \mathrm{dl}$, arterial blood pressure: systolic blood pressure $>130 \mathrm{mmHg}$ or diastolic blood pressure $>85 \mathrm{mmHg}$ and baseline glucose $>100 \mathrm{mg} / \mathrm{dl}$.

\section{Glycemic load and macronutrient intake}

Twenty-four hour recall surveys were used on weekdays, excluding holidays, following Baranowski guidelines. ${ }^{16}$ The mother and/or caregiver were interviewed (father, grandmother, etc.), as well as the child. Intake was recorded in domestic units of measurement -like cups and spoons of different sizes- to analyze the nutritional intake during the entire day. Daily energy (kcal), carbohydrate $(\mathrm{g})$, protein $(\mathrm{g})$ and fat $(\mathrm{g})$ intake was calculated using Peruvian tables of food composition ${ }^{17}$ and the Table of industrialized food composition. ${ }^{18}$ Moreover, the percentage of each of the nutrients was calculated taking into account the kilocalories consumed by each study subject.

GL was calculated based on the GI in each food, obtained from the international tables of Glycemic Index ${ }^{10,19}$ according to the net carbohydrate content in grams between the constant $100 ;{ }^{9}$ the result was a numeric value (without units). Goluch-Koniuszy and Bonczek ${ }^{20}$ classify the total GL consumed in a day as low daily GL $\leq 80$, medium daily GL from 80 to 119 and high daily GL $\geq 120$. Total GL and GL per meal were obtained (breakfast, mid-morning, lunch, afternoon and dinner). GL was categorized into tertiles; and high, medium and low GL categories were generated for each of them. 


\section{Other outcome measures}

Through a survey applied both to the caregiver and the child or adolescent, information was collected on sex (male/female), age (months), family history (father, mother or grandparents) of diabetes (yes/no), hypertension (yes/no), dyslipidemia (yes/no), obesity (yes/no) and level of physical activity (inactive/ active), classified according to the physical activity guidelines by the Ministry of Education of Spain. ${ }^{21}$

\section{Ethics}

The study was approved by the Ethics and Research Committee of the National Institute for Children's Health (1338-CEI-INSN-2014) and Universidad Peruana de Ciencias Aplicadas (CEI-559-05). Written consent and assent were obtained; the database was anonymous and confidentiality of each case was kept. After the interview, patients received a nutritional treatment plan.

\section{Data analysis}

A double-entry database was generated and then analyzed using the STATA statistical software, v13.0. Categorical outcome measures were described using absolute and relative frequencies. Numerical outcome measures did not have a normal distribution after being verified using the Shapiro-Wilk test; therefore, they were reported as median values and interquartile ranges (IQR). The association between categorical outcome measures and the presence of MS was assessed using a chi ${ }^{2}$ test or Fisher's exact test, as applicable; for the case of numerical outcome measures, significant rank-sum test was used.

Lastly, in order to assess the association between GL in tertiles, using the lower tertile as reference (total and per meal) and the presence of MS, the PR and 95\% CI were calculated using crude Poisson regression models with crude, robust variance and adjusted by age, sex, physical activity, family history of diabetes, dyslipidemia, obesity and hypertension, and total intake of carbohydrates in tertiles. The selection of these adjustment outcome measures followed an epidemiological model, since in the bivariate analysis no outcome measure showed a statistically significant relationship $(p<0.05)$.

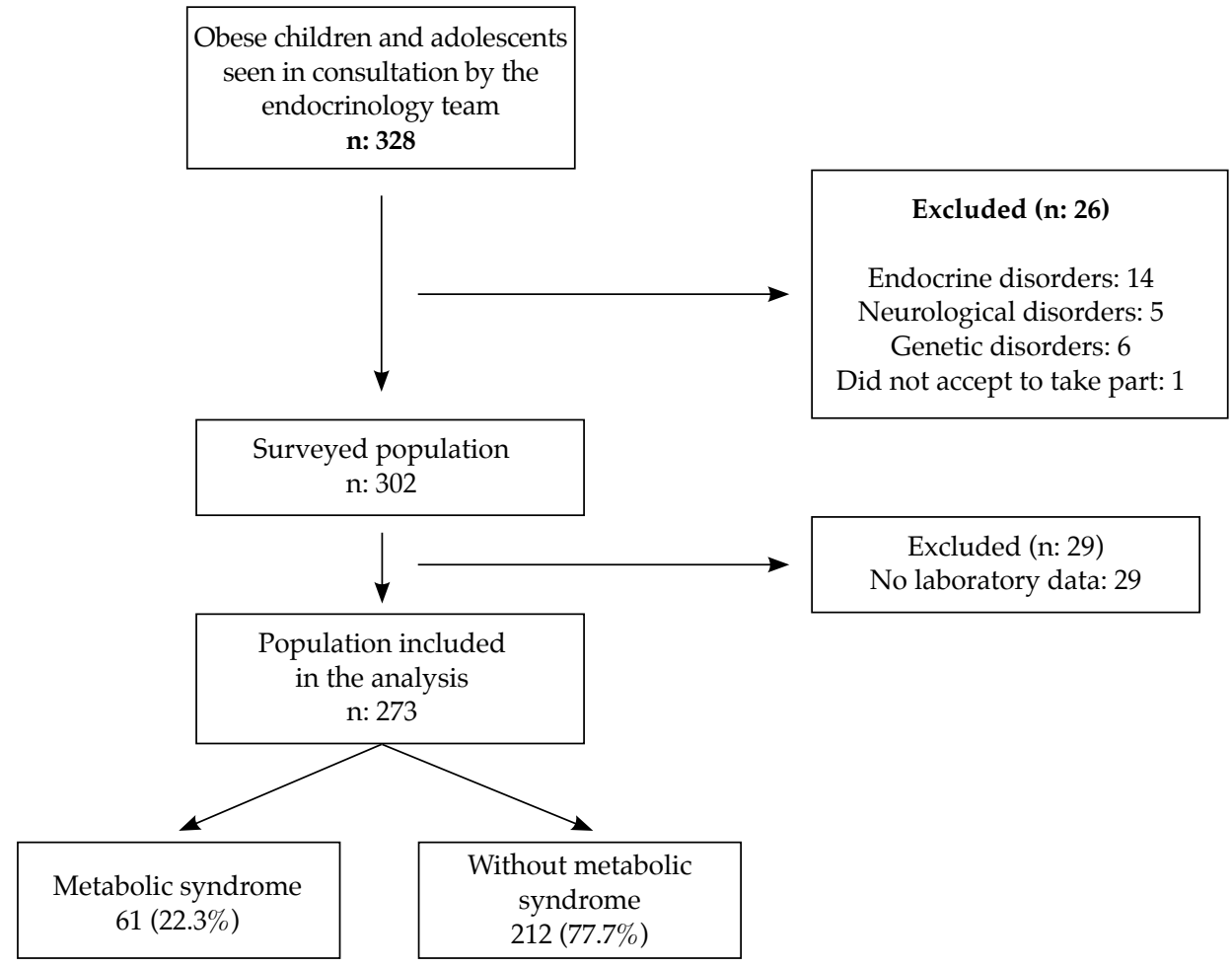


TABLE 1. Characteristics of obese children and adolescents under pediatric care in Lima, Peru

\begin{tabular}{lcc}
\hline Outcome measures & $\mathbf{n}=\mathbf{2 7 3}$ & $\mathbf{( \% )}$ \\
\hline Sex & & \\
$\quad$ Male & 143 & $(52.4)$ \\
Age (months) & & $(30.0)$ \\
Physical activity & 134 & \\
$\quad$ Inactive & & $(94.9)$ \\
Family history & 259 & \\
$\quad$ Diabetes & & $(53.5)$ \\
$\quad$ Hypertension & 146 & $(58.6)$ \\
$\quad$ Dyslipidemia & 160 & $(45.1)$ \\
$\quad$ Obesity & 123 & $(71.4)$ \\
Metabolic disorders (IDF) & 195 & \\
$\quad$ Abdominal obesity & & $(81.7)$ \\
$\quad$ Low HDL & 223 & $(63.7)$ \\
$\quad$ Hypertriglyceridemia & 174 & $(29.7)$ \\
$\quad$ Abnormal baseline glycemia & 81 & $(5.9)$ \\
$\quad$ High blood pressure & 16 & $(5.1)$ \\
Syndrome components & 14 & \\
$\quad$ None & & $(4.8)$ \\
$\quad$ One & 13 & $(28.2)$ \\
Two & 77 & $(44.7)$ \\
Three & 122 & $(20.9)$ \\
Four & 57 & \\
Metabolic syndrome & 4 & $(22.3)$ \\
$\quad$ Yes & & \\
\hline
\end{tabular}

${ }^{*}$ Median and interquartile range.

IDF: International Diabetes Federation;

HDL: high density lipoprotein.

\section{RESULTS}

Of the 328 obese children and adolescents treated at the Department of Endocrinology, 26 were not surveyed due to exclusion criteria. Three hundred and two (302) of them were surveyed, and 29 of them did not have laboratory data. Therefore, 273 patients were included in the final analysis (Figure 1). No differences were found between excluded and included patients as regards age, BMI and sex $(p>0.05)$.

The median age of the population was 11 years and 2 months (p 25-p 75: 124.5-154.5); 52.4\% were male and $94.9 \%$ were physically inactive. The average BMI was $27.2 \mathrm{~kg} / \mathrm{m} 2$. In relation to family history, the most significant was obesity $(71.2 \%)$, followed by hypertension (58.6\%). MS prevalence was $22.3 \%$; only $4.8 \%$ of patients did not have an MS component. The most prevalent components were abdominal obesity $(81.7 \%)$ and a low HDL value $(63.7 \%)$ (Table 1$)$. Finally, in the bivariate analysis no association was found between the demographic or history outcome measures and MS ( $p>0.05$, Table 2).

The median daily intake of energy was 2275 kcal (p 25-p 75: 1851.05-3024) and carbohydrates accounted for $62 \%$ of the daily caloric intake.

TABLE 2. Characteristics of obese children and adolescents with and without metabolic syndrome

\begin{tabular}{|c|c|c|c|c|c|}
\hline & \multicolumn{2}{|c|}{ With MS (n= 61) } & \multicolumn{2}{|c|}{ Without MS $(n=212)$} & \multirow[t]{2}{*}{$p^{* *}$} \\
\hline & $\mathbf{n}$ & $(\%)$ & & $(\%)$ & \\
\hline Age $^{*}$ & 137 & $(26.5)$ & 133.5 & $(30.0)$ & 0.161 \\
\hline \multicolumn{6}{|l|}{ Sex } \\
\hline Male & 28 & (19.6) & 115 & $(80.4)$ & \multirow[t]{2}{*}{0.250} \\
\hline Female & 33 & $(25.4)$ & 97 & $(74.6)$ & \\
\hline \multicolumn{6}{|c|}{ Physical activity $^{\dagger}$} \\
\hline Inactive & 59 & (22.8) & 200 & $(77.2)$ & \multirow[t]{2}{*}{0.742} \\
\hline Active & 2 & (14.3) & 12 & (85.7) & \\
\hline \multicolumn{6}{|c|}{ Family history } \\
\hline \multicolumn{6}{|c|}{ Diabetes } \\
\hline Yes & 32 & (21.9) & 114 & $(77.2)$ & \multirow[t]{2}{*}{0.856} \\
\hline No & 29 & $(22.8)$ & 98 & (78.1) & \\
\hline \multicolumn{6}{|c|}{ Hypertension } \\
\hline Yes & 38 & $(23.8)$ & 122 & $(76.2)$ & \multirow[t]{2}{*}{0.507} \\
\hline No & 23 & $(20.4)$ & 90 & (79.6) & \\
\hline \multicolumn{6}{|l|}{ Dyslipidemia } \\
\hline Yes & 28 & $(22.8)$ & 95 & $(77.2)$ & \multirow[t]{2}{*}{0.880} \\
\hline No & 33 & $(22.0)$ & 117 & $(78.0)$ & \\
\hline \multicolumn{6}{|l|}{ Obesity } \\
\hline Yes & 45 & $(23.1)$ & 150 & (76.9) & \multirow[t]{2}{*}{0.646} \\
\hline No & 16 & (20.5) & 62 & (79.5) & \\
\hline
\end{tabular}

${ }^{*}$ Median (interquartile range), Wilcoxon rank-sum test.

${ }^{* *} \mathrm{Chi}^{2}$.

† Fisher's exact test.

MS: Metabolic syndrome. 
GL median was 213.3 (p 25- p 75: 164.8-287.35), which was high $(\geq 120)$ in $90.8 \%$ of studied patients. The higher GL was observed after lunch (71.9), followed by dinner (47.0) and breakfast (36.8). No differences were found between participants with and without MS with respect to outcome measures related to food consumption (carbohydrates, proteins and fat) (Table 3), except for the GL consumed during lunch $(p=0.033)$.

The study also evaluated the association between total GL and meal times with MS, comparing the upper and medium GL tertiles with the lower tertile. After adjusting by demographic outcome measures, history and amount of carbohydrates, it was observed that those with higher total GL consumption were more likely to develop MS (PR: $4.5 ; 95 \% \mathrm{CI}$ : 1.3-15.31), compared to those with lower GL consumption. A similar trend was found in relation to lunch (PR 1.68; 95\% CI: 0.86-3.26), but not for other meal times (Table 4).

\section{DISCUSSION}

\section{Glycemic load and metabolic syndrome}

Obese children and adolescents with consumption of food with a high GL are at a higher risk of developing MS. No previous studies have been found concerning this association; however, there are studies that are looking into its association with low HDL levels. ${ }^{22}$ It is important to note that the model became significant after adjusting by the amount of consumed carbohydrates, which means that the result is more affected by the quality of the carbohydrate than by its quantity.

It has been shown that consuming foods with a high GL is related to the development of stroke and heart disease. ${ }^{23}$ The prolonged intake of food with a high GL is related to insulin resistance, whether due to the loss of pancreatic function, or the excessive production of insulin, or to the glucotoxicity of beta cells. ${ }^{8}$ Therefore, it is important to assess the consumption of carbohydrates in the diet of children and adolescents, considering their quantity and quality, with the aim of preventing future problems, such as MS, and a potential chronic disease.

\section{Metabolic syndrome and its components}

This research found a prevalence of $22.3 \%$ of MS in obese children and adolescents, according to IDF criteria. A metanalysis shows prevalences between $23.2 \%$ and $30.2 \%$ of MS in obese children and adolescents from different geographical areas, such as Europe, America (North, Central and South), Middle East (including Tunisia, Turkey and Iran) and the Far East (including India, South Korea and China). ${ }^{4}$ A previous study conducted in Peru found a prevalence of $22.9 \% .{ }^{12}$ While prevalences are relatively similar to our findings, the population of obese children is steadily increasing, which means that the number of MS cases will increase in the adult population. ${ }^{24}$

While MS studies use different diagnostic

TABLE 3. Association between food consumption, glycemic load and the presence of metabolic syndrome

\begin{tabular}{|c|c|c|c|c|c|c|c|}
\hline & \multicolumn{2}{|c|}{ Total $(n=273)$} & \multicolumn{2}{|c|}{ With MS (n= 61) } & \multicolumn{2}{|c|}{ Without MS (n= 212) } & \multirow[t]{2}{*}{$p$} \\
\hline & Median & (IQR) & Median & (IQR) & Median & (IQR) & \\
\hline \multicolumn{8}{|l|}{ Glycemic load } \\
\hline Total & 213.3 & $(122.6)$ & 247.1 & $(119.7)$ & 211.3 & $(122.2)$ & 0.190 \\
\hline Breakfast & 36.8 & (29.1) & 41.8 & $(37.7)$ & 35.7 & $(27.0)$ & 0.298 \\
\hline Mid-morning & 31.6 & $(36.0)$ & 36.4 & $(36.5)$ & 30.4 & $(34.7)$ & 0.220 \\
\hline Lunch & 71.9 & $(47.6)$ & 81.5 & (43.8) & 68.4 & (48.3) & 0.033 \\
\hline Afternoon & 14.8 & $(24.9)$ & 15.5 & $(26.8)$ & 14.4 & $(24.9)$ & 0.995 \\
\hline Dinner & 47.0 & $(37.2)$ & 45.4 & $(38.9)$ & 47.3 & $(36.9)$ & 0.942 \\
\hline \multicolumn{8}{|l|}{ Total macronutrients } \\
\hline Energy (kcal) & 2275.0 & $(1172.9)$ & 2394.6 & (1289.4) & 2243.4 & (1096.9) & 0.302 \\
\hline Carbohydrates (g) & 352.9 & $(189.0)$ & 387.2 & $(177.1)$ & 350.0 & $(188.9)$ & 0.280 \\
\hline Protein $(\mathrm{g})$ & 86.4 & $(39.5)$ & 88.5 & $(45.9)$ & 86.2 & $(38.6)$ & 0.745 \\
\hline Fat $(\mathrm{g})$ & 58.4 & $(38.7)$ & 61.4 & $(40.4)$ & 57.9 & $(37.6)$ & 0.191 \\
\hline \multicolumn{8}{|c|}{ Percentage of daily intake } \\
\hline Carbohydrates (\%) & 62.0 & $(10.0)$ & 63.0 & $(9.0)$ & 62 & $(10.0)$ & 0.755 \\
\hline Proteins $(\%)$ & 15.0 & $(4.0)$ & 14.0 & $(3.0)$ & 15 & $(4.0)$ & 0.170 \\
\hline Fat $(\%)$ & 23.0 & $(11.0)$ & 24.0 & $(10.0)$ & 23 & $(10.0)$ & 0.401 \\
\hline
\end{tabular}

MS: metabolic syndrome, IQR: interquartile range. 
criteria -contributing to the variability of prevalences- ${ }^{4}$ there are also ethnic and dietetic factors. For example, the Peruvian diet consists of a high-carbohydrate content, ${ }^{1}$ and MS usually has certain characteristics in the adult Peruvian population. The most important ones are a higher frequency of abdominal obesity and low HDL levels, ${ }^{24,25}$ which, in our study, were present in $81.7 \%$ and $63.7 \%$ of cases, respectively. These findings should be studied in the future to elucidate if the presence of these MS components in the Peruvian population is related to a diet or a genetic component, or both. These characteristics may be considered in the assessment of children at risk of developing MS, since they are the first to be present.

\section{High glycemic load and meal times}

The median value for the total GL consumed in a day was 213.3, which is almost twice as much of what is considered a high GL in a diet $(\geq 120) .{ }^{20}$ Lunch was the meal with a higher GL intake, with a median of 71.9. In children between 6 and 7 years of age in Hong Kong, at different meal times, the highest percentage of GL was consumed at lunch, and white rice was accountable for almost half of the GL in this meal time. ${ }^{26}$ Considering the evidence above mentioned, it is observed that the meal time with the highest GL content is lunch, which is mainly related to the consumption of rice and cereals. ${ }^{27}$

The only study similar to ours was conducted in Australia, where it was found that a high GL at breakfast was related to MS only in female adolescents (OR 1.15; 95\% CI: 1.04-1.27) while not in male adolescents (OR 0.83, 95\% CI: 0.64-1.07). However, this population was not characterized by being obese, as was the case in our study. ${ }^{8}$ The association found was modest, but supported our findings of an association between GL and MS.

\section{Limitations}

Since this was a cross-sectional study, it is not possible to show causality nor temporality. Longitudinal studies would allow for corroboration of the findings in this study. The

TABLE 4. Association between glycemic load and the presence of metabolic syndrome

\begin{tabular}{|c|c|c|c|c|c|c|}
\hline & \multicolumn{2}{|c|}{ MS } & \multicolumn{2}{|c|}{ Crude model } & \multicolumn{2}{|c|}{ Adjusted model } \\
\hline & $\mathbf{n}$ & $(\%)$ & PR & $(95 \% \mathrm{CI})$ & PR & $(95 \% \mathrm{CI})$ \\
\hline \multicolumn{7}{|l|}{ Total glycemic load } \\
\hline High $(>262.4)$ & 26 & (28.6) & 1.53 & $(0.89-2.62)$ & 4.50 & $(1.33-15.31)$ \\
\hline Medium (184.5-262.4) & 18 & $(19.8)$ & 1.05 & $(0.58-1.92)$ & 1.35 & $(0.53-3.42)$ \\
\hline Low $(\leq 184.5)$ & 17 & $(18.7)$ & 1.00 & Reference & 1.00 & Reference \\
\hline \multicolumn{7}{|c|}{ Glycemic load after breakfast } \\
\hline High $(>46.6)$ & 25 & $(27.5)$ & 1.25 & $(0.75-2.09)$ & 1.15 & $(0.65-2.02)$ \\
\hline Medium (27.9-46.6) & 16 & $(17.6)$ & 0.80 & $(0.44-1.44)$ & 0.77 & $(0.42-1.41)$ \\
\hline Low $(\leq 27.9)$ & 20 & $(22.0)$ & 1.00 & Reference & 1.00 & Reference \\
\hline \multicolumn{7}{|c|}{ Glycemic load at mid-morning } \\
\hline High $(>42.5)$ & 27 & $(29.7)$ & 1.50 & $(0.89-2.53)$ & 1.46 & $(0.81-2.64)$ \\
\hline Medium (22.5-42.5) & 16 & $(17.6)$ & 0.89 & $(0.48-1.63)$ & 0.80 & $(0.43-1.50)$ \\
\hline Low $(<22.5)$ & 18 & $(19.8)$ & 1.00 & Reference & 1.00 & Reference \\
\hline \multicolumn{7}{|l|}{ Glycemic load at lunch } \\
\hline High $(>85.1)$ & 25 & $(27.5)$ & 1.67 & $(0.94-2.95)$ & 1.68 & $(0.86-3.26)$ \\
\hline Medium (56.2-85.1) & 21 & $(23.1)$ & 1.40 & $(0.77-2.54)$ & 1.43 & $(0.81-2.55)$ \\
\hline Low $(<56.2)$ & 15 & $(16.5)$ & 1.00 & Reference & 1.00 & Reference \\
\hline \multicolumn{7}{|c|}{ Glycemic load in the afternoon } \\
\hline High $(>23.5)$ & 19 & $(20.9)$ & 1.19 & $(0.65-2.16)$ & 1.17 & $(0.63-2.18)$ \\
\hline Medium (8.1-23.5) & 26 & $(28.6)$ & 1.63 & $(0.94-2.82)$ & 1.56 & $(0.90-2.76)$ \\
\hline Low $(<8.1)$ & 16 & $(17.6)$ & 1.00 & Reference & 1.00 & Reference \\
\hline \multicolumn{7}{|l|}{ Glycemic load at dinner } \\
\hline High $(>58.1)$ & 21 & $(23.1)$ & 1.11 & $(0.64-1.91)$ & 1.10 & $(0.57-2.05)$ \\
\hline Medium (35.4-58.1) & 21 & $(23.1)$ & 1.11 & $(0.64-1.91)$ & 1.15 & $(0.66-2.02)$ \\
\hline Low $(<35.4)$ & 19 & $(20.9)$ & 1.00 & Reference & 1.00 & Reference \\
\hline
\end{tabular}

Crude Model: Poisson regression with robust variance.

Adjusted Model: Adjusted by age, sex and physical activity, family history of diabetes, dyslipidemia, obesity and hypertension and total consumption of carbohydrates in tertiles.

MS: Metabolic syndrome; CI: Confidence interval; PR: Prevalence ratio. 
study population has specific characteristics (obese children and adolescents treated at an endocrinology office in a hospital); therefore, results cannot be extrapolated to other settings. Studies in non-obese populations should help confirm these findings.

Twenty-four hour recall could only be administered once, and the ideal approach is to use it two or three times. Nevertheless, the recall method is still a better tool than the survey to assess food frequency. ${ }^{22}$ Moreover, the pubertal development was not considered, which may influence the MS although values were adjusted by age. ${ }^{28}$ Patients with a previous diagnosis of diabetes were excluded because they were already under nutritional treatment, which modified their GL. It should also be noted that the GL of a determined food may vary depending on how it is prepared (e.g. potatoes vs. mashed potatoes); however, these differences based on the combination of different foods are not significant to affect the glycemic response and, likewise, the GL. ${ }^{29}$

\section{Implications}

It is important not only to assess the quantity of carbohydrates consumed but also their quality. This may contribute to the development of better diet plans for these population groups. It may be possible to initially change the quality of carbohydrates, to afterwards gradually reduce their volume. This would improve adherence, and it is an approach that warrants further research. ${ }^{30}$

Our findings support the significance of using GI and GL for the management of noncommunicable diseases through diet. ${ }^{7}$

\section{CONCLUSIONS}

At least one out of five children and adolescents who seek consultation in relation to obesity at the national pediatric referral hospital in Peru suffers from MS, which is associated to a high GL consumption. To choose an adequate diet plan for these groups, it is important to consider not only the quantity of carbohydrates, but also their quality, based on the GL.

\section{REFERENCES}

1. Liria R. Consecuencias de la obesidad en el niño y el adolescente: un problema que requiere atención. Rev Peru Med Exp Salud Pública 2012;29(3):357-60.

2. Romero-Velarde E, Campollo-Rivas O, Castro-Hernández $\mathrm{JF}$, et al. Hábitos de alimentación e ingestión de calorías en un grupo de niños y adolescentes obesos. Bol Med Hosp Infant Mex 2006;63(3):187-95.
3. Pedrozo W, Castillo Rascón M, Bonneau G, et al. Síndrome metabólico y factores de riesgo asociados con el estilo de vida de adolescentes de una ciudad de Argentina, 2005. Rev Panam Salud Pública 2008;24(3):149-60.

4. Friend A, Craig L, Turner S. The prevalence of metabolic syndrome in children: a systematic review of the literature. Metab Syndr Relat Disord 2013;11(2):71-80.

5. Alberti KG, Zimmet $P$, Shaw J, et al. The metabolic syndrome-a new worldwide definition. Lancet 2005;366(9491):1059-62.

6. Hanson R L, Imperatore G, Bennett P H, et al. Components of the "metabolic syndrome" and incidence of type 2 diabetes. Diabetes 2002;51(10):3120-7.

7. Zimmet $P$, Alberti KG, Kaufman F, Tajima N, et al. The metabolic syndrome in children and adolescents-an IDF consensus report. Pediatr Diabetes 2007;8(5):299-306.

8. Nicholl A, De Heaume M, Mori TA, et al. Higher breakfast glycaemic load is associated with increased metabolic syndrome risk, including lower HDL-cholesterol concentrations and increased TAG concentrations, in adolescent girls. Br J Nutr 2014;112(12):1974-83.

9. Arteaga Llona A. El índice glicémico: una controversia actual. Nutr Hosp 2006;21(2):56-60.

10. Foster-Powell K, Holt SH, Brand-Miller JC. International table of glycemic index and glycemic load values: 2002. Am J Clin Nutr 2002;76(1):5-56.

11. World Health Organization, et al. WHO AnthroPlus for personal computers manual: software for assessing growth of the world's children and adolescents. Geneva: WHO; 2009. [Accessed on: January 17, 2017.] Available at: http:/ / www.who.int/growthref/tools/who_anthroplus_ manual.pdf.

12. Pajuelo J, Bernui I, Nolberto V, et al. Síndrome metabólico en adolescentes con sobrepeso y obesidad. An Fac Med (Lima) 2007;68(2):143-9.

13. Lohman TG, Roche F, Martorell R. Anthropometric standardization reference manual. Illinois: Human Kinetics Books; 1988.

14. Fernández, JR, Redden DT, Pietrobelli A, et al. Waist circumference percentiles in nationally representative samples of African-American, European-American, and Mexican-American children and adolescents. J Pediatr 2004;145(4):439-44.

15. Iniciativa Panamericana sobre la Hipertensión. Reunión de trabajo sobre la medición de la presión arterial: recomendaciones para estudios de población. Rev Panam Salud Pública 2003;14(5):303-5.

16. Baranowski T. 24-Hour dietary recall and food record methods. In Willet W. Nutritional Epidemiology. 3rd ed. Oxford: Oxford University Press; 1998. Pages.49-69.

17. Reyes García M, Gómez-Sanchez Prieto I, Espinoza Barrientos C, et al. Tablas peruanas de composición de alimentos. 8.va ed. Lima: Ministerio de Salud, Instituto Nacional de Salud; 2009. [Accessed on: January 17, 2017.] Availableat:http:/ / www.ins.gob.pe/insvirtual/images / otrpubs/pdf/Tabla\%20de $\% 20$ Alimentos.pdf.

18. Bejarano E, Bravo M, Huamán $M$, et al. Tabla de composición de alimentos industrializados. Lima: Centro Nacional de Alimentación y Nutrición, Instituto Nacional de Salud; 2002. [Accessed on: January 17, 2017.] Available at: http://www.um.es/lafem/ Nutricion/DiscoLibro/03-Alimentos/Complementario/ TablaComposicionalimentosIndustrializados.pdf.

19. AtkinsonFS, Foster-Powell K, Brand-MillerJC. International tables of glycemic index and glycemic load values: 2008. Diabetes Care 2008;31(12): 2281-3.

20. Goluch-Koniuszy Z, Bonczek M. Glycemic index and glycemic load of thirteen year old children whose waist 
circumference $(\mathrm{WC}) \geq 90$ percentile dependent on BMI. Acta Sci Pol Technol Aliment 2011;10(2):245-65.

21. Aznar Laín S, Webster T. Actividad física y salud en la infancia y la adolescencia. Guía para todas las personas que participan en su educación. Madrid: Ministerio de Educación; 2006.

22. Denova-Gutiérrez E, Huitrón-Bravo G, Talavera JO, et al. Dietary glycemic index, dietary glycemicload, blood lipids, and coronary heart disease. J Nutr Metab 2010;2010:170680.

23. Matía Martín P, Lecumberri Pascual E, Calle Pascual AL. Nutrición y síndrome metabólico. Rev Esp Salud Pública 2007;81(5):489-505.

24. Cárdenas Quintana H, Sánchez Abanto J, Roldán Arbieto $\mathrm{L}$, et al. Prevalencia del síndrome metabólico en personas a partir de 20 años de edad: Perú, 2005. Rev Esp Salud Pública 2009;83(2):257-65.

25. Rosas A, Lama G, Llanos-Zavalaga F, et al. Prevalencia de obesidad e hipercolesterolemia en trabajadores de una institución estatal de Lima-Perú. Rev Perú Med Exp Salud Pública 2002;19(2):87-92.
26. Hui LL, Nelson EA. Meal glycaemic load of normal-weight and overweight Hong Kong children. Eur J Clin Nutr 2006;60(2):220-7.

27. Instituto Nacional de Estadística e Informática. Perú: Consumo per cápita de los principales alimentos 2008-2009. Lima:INEI;2012. [Accessed on:January 17, 2017.] Available at: https:/ / www.inei.gob.pe/media/MenuRecursivo/ publicaciones_digitales/Est/Lib1028/index.html.

28. Burrows R, Leiva L, Weistaub G, et al.Síndrome metabólico en niños y adolescentes: asociación con sensibilidad insulínica y con magnitud y distribución de la obesidad. Rev Med Chile 2007;135(2):174-81.

29. Wolever TM, Jenkins DJ, Jenkins AL, et al. The glycemic index: methodology and clinical implications. Am J Clin Nutr 1991;54(5):846-54.

30. Gnagnarella P, Gandini S, La Vecchia C, et al. Glycemic index, glycemic load, and cancer risk: a meta-analysis. $\mathrm{Am}$ J Clin Nutr 2008;87(6):1793-801. 